\title{
LA VICEPRESIDENCIA EN AMÉRICA COMO DESAFÍO A LA DEMOCRACIA REPRESENTATIVA: LOS CASOS DE ESTADOS UNIDOS, BRASIL Y ARGENTINA
}

\author{
THE VICE PRESIDENCY IN AMERICA AS A CHALLENGE \\ TO REPRESENTATIVE DEMOCRACY: THE CASES OF \\ THE US, BRAZIL AND ARGENTINA
}

\section{LA VICE-PRÉSIDENCE EN AMÉRIQUE EN TANT QUE DÉFI ENVERS LA DÉMOCRATIE REPRÉSENTATIVE: LES CAS DES ÉTATS-UNIS, DU BRÉSIL ET DE L'ARGENTINE}

\author{
Ariel SRibman MitTelman* \\ Universidad en Gerona, España \\ ariel.sribman@udg.edu
}

\begin{abstract}
Resumen: A partir de la tercera ola de democratización, la ciencia política ha debatido extensamente el desempeño del presidencialismo en América Latina y sus efectos sobre la estabilidad democrática. Sin embargo, ese debate dejó al margen una figura clave: la vicepresidencia. El objetivo del presente artículo es reflexionar sobre este cargo, presente prácticamente en toda América, como desafío al carácter representativo de la democracia, entroncando con el debate existente sobre el presidencialismo y la estabilidad política de las democracias americanas. A partir de tres casos, Brasil, Argentina y Estados Unidos, se plantea el carácter fijo (no removible por el presidente) y los mecanismos previstos para su elección como factores que merman el carácter representativo de la vicepresidencia, generando inestabilidad y déficit de legitimidad del Ejecutivo. De lo anterior se concluye la necesidad de introducir reformas en la vicepresidencia o considerar su sustitución por otro método sucesorio.
\end{abstract}

Palabras clave: vicepresidente; América Latina; Estados Unidos; democracia representativa; legitimidad.

* El autor desea agradecer a los revisores anónimos de Foro Internacional, cuyos comentarios y sugerencias ayudaron a mejorar y clarificar el manuscrito original. 
Abstract: Since the Third Wave of democratization, political science has extensively debated the performance of the presidential model in Latin America and its effects on democratic stability. However, that debate has ignored a key figure: the vice presidency. The objective of this article is to reflect on this position, which exists practically throughout the Americas, as a challenge to the representative character of democracy, in connection with the existing debate on presidentialism and the political stability of American democracies. Based on three cases-Brazil, Argentina and the United States-this article considers the fixed character of the role (not removable by the president) and the mechanisms provided for his election as factors that diminish the representative character of the vice presidency and lead to instability and a lack of legitimacy of the Executive. Drawing on these factors, this article concludes there is a need to introduce reforms to the vice presidency, or consider its replacement by another mode of succession.

Keywords: vice president; Latin America; United States; representative democracy; legitimacy.

\section{Traducción de Fionn Petch, cm Idiomas}

RÉsumé : Depuis la troisième vague de démocratisation, la science politique a longuement débattu de la performance du présidentialisme en Amérique latine et de ses effets sur la stabilité démocratique. Cependant, ce débat a laissé de côté un personnage clé : la vice-présidence. L'objectif de cet article est de réfléchir sur cette position, présente pratiquement dans toute l'Amérique, comme une remise en cause du caractère représentatif de la démocratie, en lien avec le débat existant sur le présidentialisme et la stabilité politique des démocraties américaines. Sur la base de trois cas : Brésil, Argentine et États-Unis, le caractère fixe (non révocable par le président) et les mécanismes prévus pour son élection sont considérés comme des facteurs qui réduisent le caractère représentatif de la vice-présidence, générant instabilité et déficit de légitimité de l'Exécutif. De ce qui précède, on peut conclure à la nécessité d'introduire des réformes dans la vice-présidence ou d'envisager son remplacement par un autre mode de succession. 


\begin{abstract}
Mots-clés : vice-président ; Amérique latine; États Unis; démocratie représentative; légitimité.
\end{abstract}

Traducción de Rafael Segovia, cm Idiomas

Fecha de recepción: octubre de 2020.

Fecha de aceptación: noviembre de 2021.

\title{
INTRODUCGIÓN
}

$1 \begin{aligned} & \text { finales del siglo xviı nacieron dos de las experiencias } \\ & \text { democráticas más emblemáticas de la edad contempo- } \\ & \text { ránea: la República francesa y Estados Unidos de Amé- }\end{aligned}$ rica (EE.UU.). La suplantación de modelos monárquicos por formas de gobierno más pluralistas, incluyentes y limitadas traería aparejado, entre muchos otros problemas, el de la sucesión: si el poder del gobernante deja de ser vitalicio, y si además ya no se cuenta con un sucesor automático por razón de linaje, ¿cómo cubrir el vacío de poder que surge cuando el titular del gobierno abandona su cargo?

Esta problemática fue solucionada en el caso de Estados Unidos a través de la figura del vicepresidente y, unas décadas más tarde, se hizo lo propio en una gran cantidad de países latinoamericanos que, recién independizados de España y Portugal, se constituyeron en repúblicas presidencialistas que, siguiendo el modelo estadounidense, instituyeron la figura del vicepresidente como instrumento sucesorio.

Ahora bien, la implementación de la vicepresidencia no estuvo -ni está- exenta de conflicto. En el caso de Estados Unidos, muy pronto fueron evidentes algunos de sus defectos más graves. De ahí que, tras apenas 15 años de vida de la Constitución, se incorporara a ésta, en 1804, la XII Enmienda, que modificaba la forma de elección de presidente y vicepresidente. Un siglo y medio después, Estados Unidos seguía implementando modificaciones para paliar los defectos de 
la vicepresidencia: en 1967, la xxv Enmienda corregía -como se verá en detalle más adelante-falencias de origen del texto constitucional respecto a este cargo.

En América Latina, en cambio, la reacción frente a los defectos de la vicepresidencia ha sido notablemente más tibia o, en algunos países, nula. La historia del cargo incluye episodios de gran conflictividad en la práctica totalidad de los Estados que lo incorporaron a su diseño institucional. En algunos casos, se plantearon reformas constitucionales que promovieron su eliminación; ${ }^{1}$ pero allí donde la vicepresidencia se mantuvo presente, ni se ha modificado la forma de elección ni se han incorporado a los textos constitucionales mecanismos para prevenir o solucionar la problemática más habitual del vicepresidente una vez en el cargo. De forma más específica, no se han tomado medidas para abordar el defecto particular del que se ocupa este estudio: el potencial déficit representativo de la vicepresidencia.

Este artículo investiga precisamente cómo en la vicepresidencia de corte estadounidense (la del propio país norteamericano y la de los países latinoamericanos que copiaron su modelo) se distorsiona la representatividad democrática. Dicho de otra manera: ¿en qué medida esta vicepresidencia supone una amenaza para el carácter representativo de las democracias? Se intentará responder a esta pregunta tomando en consideración tres casos: Estados Unidos, Argentina y Brasil.

A partir de la tercera ola de democratización en América Latina, la literatura sobre el presidencialismo, sus defectos y sus peligros, fue notablemente prolífica. Al texto seminal de Linz $^{2}$ siguieron las propuestas de Mainwaring, ${ }^{3}$ Mainwaring

${ }^{1}$ L. Marsteintredet, "La vicepresidencia y los problemas de la sucesión presidencial en América Latina. Viejos y nuevos retos para el presidencialismo", Política y Gobierno, 26, 1 (2019), pp. 117-137.

2 J. Linz, "The Perils of Presidentialism", Journal of Democracy, 1(1) (1990), pp. 51-69.

3 S. Mainwaring, "Presidentialism, Multipartism, and Democracy. The Difficult Combination”, Comparative Political Studies, 26(2) (1993), pp. 198-228. 
y Shugart ${ }^{4}$ y Cheibub y Limongi, ${ }^{5}$ entre muchos otros. La vinculación causal del presidencialismo con la inestabilidad política se había situado en el centro del debate, aunque retrospectivamente llama la atención la ausencia de dos elementos: la comparación sistemática con Estados Unidos, donde el presidencialismo no había sido origen de inestabilidad política -o al menos no se le había considerado así-, y la inclusión de la vicepresidencia, cuya principal misión es precisamente garantizar la estabilidad y la continuidad del sistema político cuando la presidencia es origen de turbulencias. Por un lado, los expertos no se plantearon la incapacidad de la vicepresidencia para cumplir esa función elemental. Por otro lado, durante la primera generación de estos estudios, todavía no se había disparado claramente la tendencia de la vicepresidencia a ser fuente de conflictos políticos y de inestabilidad para el Ejecutivo del que forman parte. ${ }^{6}$

En virtud de lo anterior, este artículo procura introducir la figura del vicepresidente en el debate -siempre abiertosobre presidencialismo y estabilidad democrática. Se propone arrojar luz sobre las puertas que abre la vicepresidencia de molde estadounidense al déficit representativo: comprender qué elementos de su diseño institucional participan, cómo se conjugan con la cultura política del país, qué se ha hecho-y qué no- para paliarlo, cómo algunas soluciones han dado lugar a ulteriores problemas. Desde el momento en que estas situaciones han tenido lugar, se vuelve obligado considerar la posibilidad de que vuelvan a darse; por lo tanto, es necesario abordarlas. Las estadísticas acerca de la frecuencia con que se presentan estos acontecimientos, siendo un dato

${ }^{4}$ S. Mainwaring y M. Shugart, M., "Juan Linz, Presidentialism and Democracy. A Critical Appraisal", Comparative Politics, 29 (4) (1997), pp. 449-471.

${ }^{5}$ J.A. Cheibub y F. Limongi, "Democratic Institutions and Regime Survival: Parliamentary and Presidential Democracies Reconsidered", Annual Review of Political Science, 5 (2002), pp. 151-79.

${ }^{6}$ Cfr. A. Sribman, "La vicepresidencia en América Latina: un mal innecesario", América Latina Hoy, 2019, núm. 81, pp. 51-75. 
relevante para otros estudios, resulta aquí secundaria: son eventos que se han dado en el pasado reciente, y que por lo tanto forman parte del panorama político actual, que es necesario analizar y comprender en profundidad, mediante un estudio detallado, cualitativo, de cada caso.

\section{LA VICEPRESIDENCIA: UN VACÍO EN LA LITERATURA}

Pese a la frecuencia con que la vicepresidencia es origen de conflictos en la política latinoamericana, sigue siendo sorprendente la escasa atención que esta institución recibe de la comunidad académica. Los estudios sobre la vicepresidencia en América Latina son tan recientes como exiguos. Las publicaciones seminales se centran en el poder del vicepresidente en los casos en que el mecanismo constitucional de sucesión presidencial lo lleva al cargo superior, así como, por lo general, se ha estudiado la figura vicepresidencial desde la perspectiva del derecho constitucional, es decir, desde una posición teórica y formal (los trabajos al respecto son abundantes y aportan un panorama amplio cronológica e ideológicamente). ${ }^{7}$ Poco y nada ha sido dicho, en cambio, sobre el peso político que este actor ostenta desde la propia vicepresidencia y que se manifiesta tanto en el ámbito Ejecutivo como en el Senado. Tampoco se ha analizado, desde una perspectiva empírica y comparativa, el desempeño que ha tenido cada uno de los vicepresidentes. Entre las escasas aportaciones en este ámbito cabe destacar la de Linz y la de

${ }^{7}$ J. González, El Senado federal. Su constitución, facultades y privilegios. Dictámenes y discursos parlamentarios, Buenos Aires, La Facultad, 1919; G. Bidart Campos, Manual de la Constitución reformada. Buenos Aires, Ediar, 1997; M. Ekmekdjián, Manual de la Constitución argentina, Buenos Aires, Depalma, 1999; G. Badeni, Las funciones del vicepresidente de la Nación, El Derecho, 11 de agosto de 2008; D. Armesto, "El vicepresidente de la nación. Su importancia institucional”, El Derecho, (19 de septiembre de 2008), 12.094. 
Linz y Valenzuela, ${ }^{8}$ que tocaron tangencialmente la vicepresidencia al analizar los sistemas presidenciales en América Latina, así como Serrafero, Sribman, Mieres, Pampín, Bidegain, Marsteintredet y Uggla, ${ }^{9}$ que mucho más recientemente comenzaron a ocuparse de manera específica de esta institución.

En lo que interesa aquí, no existen investigaciones que aborden en profundidad el déficit representativo de la figura vicepresidencial, teniendo en cuenta la experiencia de los vicepresidentes en las últimas cuatro décadas (desde que fueron restablecidos los gobiernos democráticos en América Latina, durante la tercera ola de democratización). Marsteintredet se acerca al problema de la legitimidad del vicepresidente, pero no entra con suficiente profundidad en éste,

${ }^{8}$ J. Linz, Democracia Presidencialista o Parlamentaria, en Consejo para la Consolidación de la Democracia, Presidencialismo vs. Parlamentarismo, Buenos Aires, Eudeba, 1988; J. Linz y A. Valenzuela (eds.), The Failure of Presidential Democracy, vol. 2. The case of Latin America, Baltimore, The Johns Hopkins University Press, 1994.

${ }^{9}$ M. Serrafero, El poder y su sombra. Los vicepresidentes, Buenos Aires, Editorial de Belgrano, 1999; M. Serrafero, "La vicepresidencia y las coaliciones políticas: el caso de Argentina”, Revista de Sociologia e Política, 26 (65) (2018), pp. 15-38; A. Sribman, "La vicepresidencia argentina (19832009)", Cadernos de Estudos Latino-Americanos, 10, 2011; A. Sribman, La sucesión del poder. Una aproximación general desde experiencias de los siglos XX y XXI, Salamanca, Ediciones Universidad, 2015; Sribman, "La vicepresidencia en América Latina...", art. cit.; A. Sribman, "La vicepresidencia en México: un debate pendiente", Revista Estudios Políticos, 2019, núm. 48, pp. 73-94; P. Mieres, "Las candidaturas vicepresidenciales en las campañas electorales. El caso de Uruguay 2009", ponencia presentada en el Cuarto Congreso de Ciencia Política de Uruguay, Montevideo, 14-16 de noviembre de 2012; P. Mieres y E. Pampín, "La trayectoria de los vicepresidentes en los regímenes presidencialistas de América", Revista de Estudios Políticos, 167 (2015), pp. 99-132; G. Bidegain, "Vicepresidentes en América del Sur: una agenda de investigación", Colombia Internacional, 89 (2017), pp. 159-188; Marsteintredet, art. cit. L. Marsteintredet y F. Uggla, "Allies and Traitors: Vice-Presidents in Latin America", Journal of Latin American Studies (2019), 1-28, doi:10.1017/S0022216X18001098; F. Uggla, "The politics of vice-presidential selection in Latin America", Electoral Studies (2020), https://doi.org/10.1016/j.electstud.2020.102154 
dejando a un lado detalles políticos, legales e históricos que aquí se tendrán en cuenta.

Algo similar ocurre en Estados Unidos, donde la bibliografía académica sobre la vicepresidencia es sensiblemente más abundante y, sin embargo, es notable la ausencia de análisis sistemáticos y comparados de las tareas que cada vicepresidente efectuó durante su gestión, sus diversos grados y modos de actuación en el seno del gobierno y en su condición de presidentes del Senado, el provecho que sacaron a su paso por el tuétano de la vida política para construir vínculos o para crearse una imagen pública positiva, o sus distintas reacciones frente a las disidencias con el presidente y los efectos de tales reacciones. Entre estas obras destaca el trabajo pionero de Goldstein, de 1982; otras investigaciones minuciosas son las de Bayh, Young, Silberdick Feinberg, Walch, Purcell y Baumgartner. ${ }^{10}$

En el caso estadounidense es importante destacar, además, que la mirada investigadora está siempre limitada al propio país. Son inexistentes los estudios elaborados por investigadores norteamericanos que comparen la vicepresidencia estadounidense con aquella de otros países, como los latinoamericanos, en donde las reglas son, en su mayoría, las mismas, pero el desempeño real es notablemente distinto.

El presente artículo expondrá, en primer lugar, el origen de la vicepresidencia, para dilucidar hasta qué extremo tuvo peso en su creación la procura de representatividad democrática. A continuación, se discutirá el vínculo entre presi-

${ }^{10} \mathrm{~J}$. Baumgartner, The American Vice Presidency Reconsidered, Westport, Praeger Publishers, 2006; B. Bayh, Presidential Disability and Succession, Indianapolis y Nueva York, The Bobbs-Merrill Company, 1968; J. Goldstein, The Modern American Vice Presidency. The Transformation of a Political Institution, Princeton, University Press, 1982; L. Purcell (ed.), The Vice Presidency: A Biographical Dictionary, Nueva York, Facts on File, 1998; B. Silberdick Feinberg, Next in Line: The American Vice Presidency, Danbury, Franklin Watts, 1996; T. Walch (ed.), At the President's Side. The Vice Presidency in the Twentieth Century, Columbia, University of Missouri Press, 1997; D. Young, American Roulette. The History and Dilemma of the Vice Presidency, Nueva York, Holt, Rinehart and Winston, 1972. 
dencialismo y el carácter representativo del Poder Ejecutivo en esta forma de gobierno. En tercer lugar, se presentarán los tres casos de análisis: Estados Unidos, Argentina y Brasil. Por último, se reflexionará, a partir de los dos puntos anteriores, acerca de la relación entre democracia representativa y vicepresidencia.

La selección de estos tres casos responde a dos criterios: en primer lugar, que cada uno de ellos es ejemplo de un problema distinto para la representación: en Estados Unidos, la xxv Enmienda abre la puerta a que tanto el presidente como el vicepresidente hayan sido elegidos por métodos ajenos a la elección popular. En Argentina, la experiencia del vicepresidente Julio Cobos (2007-2011) da buena cuenta del problema de representación que puede traer aparejada la elección de una fórmula de coalición, es decir, compuesta por un presidente y un vicepresidente que no comparten partido, programa, ideología, etc.; pero en donde el vicepresidente resulta una figura problemática -a efectos de representación- sin llegar a la presidencia. En Brasil, el caso de Michel Temer parte de una situación similar a la de Cobos en Argentina; sin embargo, su llegada a la presidencia tras la destitución de Dilma Rousseff permite apreciar las consecuencias últimas de los mecanismos asociados a la sucesión vicepresidencial, y sus efectos negativos en lo que atañe a la representación.

El segundo criterio responde a un grado de similaridad en el diseño institucional del Poder Ejecutivo de los tres países, que permite identificar y analizar las diferencias en el desempeño de la vicepresidencia. Así, los tres casos estudiados son repúblicas federales, al frente de cuyos ejecutivos se encuentra una dupla presidente-vicepresidente. Los candidatos a ambos cargos concurren conjuntamente a las elecciones en una fórmula o ticket, y en los tres casos se trata de una vicepresidencia rígida, es decir, el presidente no tiene capacidad de remover al vicepresidente. ${ }^{11}$

${ }^{11}$ Sribman, "La vicepresidencia en América Latina...", art. cit. 
EL ORIGEN DE LA VICEPRESIDENCIA: MUY LEJOS DE LA REPRESENTACIÓN DEMOCRÁTICA

Tras la guerra de independencia norteamericana comenzaron los debates orientados a la redacción de una Constitución. La figura del vicepresidente no apareció hasta el final de esas sesiones y no hubiera aparecido de no haberse adoptado el sistema de Colegio electoral. En efecto, el borrador del Comité del Detalle ${ }^{12}$ proponía que ante una eventual vacancia de la presidencia, el presidente del Senado asumiera los poderes y obligaciones del jefe del Ejecutivo hasta que otro presidente fuera elegido. ${ }^{13}$

El sistema de Colegio electoral, sin embargo, otorgaba a cada elector un voto. Dado que el número de electores por estado se definía en función de su población, y que en aquellos tiempos la lealtad al propio estado era muy intensa, resultaba altamente probable que cada elector diera su voto al candidato de su tierra; en ese caso, se llegaría a un empate entre los estados más poblados y a una situación de parálisis que dejaría como única alternativa la elección del presidente por el Congreso.

En consecuencia, se acordó conceder a cada elector dos votos, quedando prohibido que ambos fueran para el mismo candidato. Así, si cada elector daba su primer voto al candidato de su propio Estado, quedaba un segundo voto que marcaría la diferencia y permitiría una definición. Sin embargo, los constituyentes notaron pronto que bajo este sistema los electores, para seguir favoreciendo a su estado de origen, echarían a perder el segundo voto, otorgándolo a un candidato sin posibilidades reales de quedarse con la presidencia.

La solución para esto fue, y así se adoptó en el texto constitucional, que ese segundo voto estuviera destinado a elegir

12 Committee of Detail; la traducción es utilizada en algunas fuentes, pero dudosa. El mencionado borrador fue entregado por el Comité el 6 de agosto de 1787.

${ }^{13}$ A. Schlesinger, Jr., "On the Presidential Succession”, Political Science Quarterly, 89 (3) (1974), p. 488. 
otro cargo: el de vicepresidente. De esta manera, cada elector emitía dos votos; de todos los candidatos, que se presentaban uniformemente a la presidencia, quien obtenía la mayor cantidad de votos se quedaba con la primera magistratura, en tanto quien lograba el segundo mayor número de votos era nombrado vicepresidente. ${ }^{14}$

Se puede afirmar, en síntesis, que la vicepresidencia nació en Estados Unidos de la necesidad de solventar inconvenientes relativos al sistema electoral para escoger presidente. Se trataba de resolver un problema de ingeniería constitucionalelectoral, no de garantizar la continuidad del programa por el que habían votado los electores, en caso de que el presidente abandonara su cargo. Más bien al contrario: si esto último ocurría, el reemplazante del presidente sería aquel que había competido con él en las elecciones, con unas propuestas presumiblemente distintas, y que había quedado en segundo puesto. Es decir, que eran altas las probabilidades de que se produjera un cambio de rumbo político y que la nueva dirección adoptada no representara a la mayoría de electores en la misma medida que la elegida en primera instancia.

El Federalista, que recoge las discusiones conducentes a la redacción de la Constitución estadounidense, dedica sólo un párrafo a la vicepresidencia. En él se defiende este cargo, aunque su función sucesoria parece ocupar un lugar secundario:

El hecho de que se nombre a una persona especial para el puesto de Vicepresidente ha sido objetado como no sólo superfluo, sino incluso perjudicial. Se sostiene que habría sido preferible autorizar al Senado para que eligiera dentro de sí mismo un funcionario que ocupara ese cargo. Pero hay dos consideraciones que parecen justificar las ideas de la convención acerca del asunto. Una es que para asegurar en todo tiempo la posibilidad de una resolución definida en ese cuerpo, es

${ }^{14}$ W. Berns, "The Insignificant Office. What the Framers Thought of the Vice Presidency", 9 de julio de 2004, National Review Online. 
necesario que el Presidente tenga únicamente voto de calidad. Y sacar al senador de un Estado de su curul, para ponerlo en la del Presidente del Senado, sería cambiar respecto a ese Estado un voto fijo por un voto eventual. La consideración restante consiste en que como el Vicepresidente puede sustituir ocasionalmente al Presidente en la suprema magistratura ejecutiva, todas las razones que apoyan el modo de elección prescrito para el uno se aplican con gran fuerza a la manera de designar al otro. ${ }^{15}$

El origen de la vicepresidencia estadounidense resulta especialmente relevante si se considera que los arquitectos de numerosas constituciones latinoamericanas imitaron los contenidos y formas de la Ley Fundamental de Estados Unidos para abordar la sucesión en sus países.

En efecto, a lo largo de las décadas siguientes a la fundación de Estados Unidos, es decir, durante la primera mitad del siglo xIX, se produjo la independencia de la mayor parte de las naciones latinoamericanas. Éstas adoptaron casi en su totalidad la forma de Estado republicana, con gobiernos de duración limitada y, en muchos casos, imitaron la figura creada por los padres fundadores de la república estadounidense para la sucesión del poder. Más adelante se apuntará cuáles son los países latinoamericanos que incorporaron un vicepresidente (o más de uno) en sus gobiernos, y qué mecanismos sucesorios se adoptaron en las constituciones sin vicepresidente. En diversos casos ha sido estudiado en qué medida la imitación de la configuración sucesoria estadounidense fue absoluta y sin debates en torno a su adecuación o inconveniencia en el contexto político nacional. ${ }^{16}$

15 A. Hamilton, J. Madison y J. Jay, El Federalista, México, Fondo de Cultura Económica, 2001 ( $1^{\text {ra }}$ ed. en inglés, 1780), p. 291.

${ }^{16}$ Cfr. N. Castro, La sorprendente historia de los vicepresidentes argentinos, Buenos Aires, Javier Vergara Editor, 2009; A. Bianchi, Historia de la formación constitucional argentina: 1810-1860, Buenos Aires, Lexis Nexis Argentina, 2007, pp. 187-198. 


\section{DEMOGRACIA REPRESENTATIVA Y PRESIDENCIALISMO}

Antes de pasar al estudio de los tres casos aquí considerados como base de reflexión, es necesario detenerse en una cuestión previa: el carácter representativo del presidencialismo, independientemente de la vicepresidencia. Esto es: ¿se puede afirmar que, vicepresidencia aparte, el presidencialismo ofrece una representación incontrovertible? ¿Se puede sostener que la vicepresidencia es la principal amenaza al carácter representativo del Ejecutivo presidencialista, o hay acaso otras anteriores? El sentido de las preguntas anteriores se explica mediante las siguientes: ¿dónde reside la representación en un sistema presidencialista: ¿en el Ejecutivo, en el Legislativo o en ambos? Puesto que el pueblo vota por los dos poderes, ¿cuál ostenta la representación en un nivel más alto?

A propósito de estas preguntas es interesante que Aragón Reyes se refiera a "una concepción europea de la democracia basada en la unidad de representación política, esto es, en el monopolio parlamentario de la legitimidad popular, que admitía muy difícilmente una dualidad de representación capaz de operar independientemente en el Legislativo y en el Ejecutivo", ${ }^{17}$ a lo que puede agregarse el siguiente postulado de Kelsen: "Aunque la democracia y el parlamentarismo no son idénticos, no cabe dudar en serio -puesto que la democracia directa no es posible en el Estado moderno- que el parlamentarismo es la única forma real en que puede plasmar la idea de la democracia dentro de la realidad social presente". ${ }^{18}$

Es decir, desde el punto de vista de cierta tradición europea de pensamiento político, esa dualidad de representación que encarna el presidencialismo sería inconcebible o, en todo caso, poco recomendable. Desde el punto de vista

${ }_{17}$ M. Aragón Reyes, Estudios sobre el Parlamento, Ciudad de México, unam, Instituto de Investigaciones Jurídicas y Cámara de Diputados, 2017, p. 32.

${ }^{18}$ H. Kelsen, Esencia y valor de la democracia, Barcelona y Buenos Aires, Labor, 1934, p. 50. 
de los padres fundadores tampoco parece que la representación haya sido un objetivo fundamental: por un lado, la opción por el presidencialismo se habría debido, fundamental, si no exclusivamente, a la búsqueda de la división de poderes y el control mutuo entre ellos, y de garantizar la independencia del Ejecutivo; por otro lado, la implementación del Colegio electoral para elegir al presidente parece haberse debido a motivos precisamente opuestos a la representación: con éste se habría procurado "moderar la participación del pueblo en la elección presidencial" y "filtrar las pulsiones populares". 19

Indudablemente, uno de los nombres a tener en cuenta al reflexionar sobre la configuración del sistema político estadounidense -y, por extensión, de los latinoamericanos que imitaron su Constitución- es el de Alexis de Tocqueville. En su Democracia en América, el francés afirma que la capacidad presidencial de veto "es una especie de apelación al pueblo". Es decir que, hasta aquí, el Ejecutivo tendría un resorte que lo presentaría como depositario de la representación popular última. Sin embargo, el veto es un recurso extraordinario. Y en esta línea continúa Tocqueville: tras definir la soberanía como "el derecho de hacer las leyes", afirma que el presidente es "el ejecutor de la ley, pero no contribuye realmente a hacerla, ya que aunque le niegue su asentimiento no puede impedir su promulgación. Así, pues, no forma parte de la soberanía; es solamente un agente". Esto es que la soberanía popular depositada en el Estado está esencialmente en manos del Legislativo y, por tanto, es éste el que debe ostentar la representación más inmediata y sin distorsiones. Tocqueville afirma que el Poder Ejecutivo está sometido al Legislativo para luego resolver con rotundidad: "En América el presidente ejerce una influencia bastante grande en los asuntos del Estado, pero no los dirige; el poder preponderante reside en la representación nacional entera. Es,

19 J. Redondo, "Orígenes y justificación del presidencialismo americano”, Cuadernos de pensamiento político, 47 (2015), pp. 63-64. 
pues, la masa del pueblo lo que hay que cambiar, y no sólo el presidente, para que las máximas de la política varíen". ${ }^{20}$

Sin duda, las cosas han cambiado enormemente desde los tiempos de Tocqueville. Hay una serie de elementos convergentes que obligan a replantearse estos postulados: la personalización de la política, ${ }^{21}$ el desarrollo del hiperpresidencialismo, ${ }^{22}$ la eclosión de los medios de comunicación de masas e internet en la política... factores que contribuyen a reelaborar la teoría sobre la representación: es indudable que los ciudadanos en sistemas presidencialistas votan en la actualidad con igual o mayor conocimiento sobre el candidato a presidente que sobre los candidatos al Legislativo -o el ideario que representan-. Por lo que resulta difícil negar que el Ejecutivo alega una potencia representativa muy superior a la que le atribuía Tocqueville. Por ello, es necesaria la reflexión sobre el carácter más o menos representativo de aquel destinado a convivir con el presidente en el Ejecutivo y, eventualmente, a reemplazarlo.

Si se aplican estos mismos planteamientos a la vicepresidencia, la pregunta que surge de inmediato es: ¿con qué legitimidad cuenta el vicepresidente en virtud de haber sido elegido en las urnas, con la misma que el presidente? En este sentido, es necesario reconocer el vacío en la literatura publicada hasta la fecha, agravado por experiencias recientes que ponen en duda la exigua teoría existente. Así, Serrafero argumenta que los votos obtenidos por las fórmulas presidenciales están realmente dirigidos al candidato a presidente, siendo el candidato a vicepresidente un receptor colateral del sufragio. ¿Se puede colegir de ello que en el caso del vicepresidente los votos no equivalen a legitimidad?

${ }^{20}$ A. de Tocqueville, La democracia en América 1, Madrid, Alianza, 1980 (1835), pp. 113-120.

${ }^{21}$ G. Maddalena, "Political Communication in the (Iconic) Trump Epoch”, European View, 15 (2) (2016), pp. 245-252.

22 S. Rose-Ackerman et al., "Hyper-presidentialism: Separation of Powers without Check and Balances in Argentina and Philippines" Berkeley Journal of International Law, 29 (1) (2011), pp. 246-333. 
A esta propuesta parece imprescindible oponer la teoría sobre selección de candidatos a vicepresidente, desarrollada sobre todo para el caso estadounidense pero de forma incipiente también para América Latina. ${ }^{23}$ Según casi la totalidad de autores en este ámbito, tal selección responde precisamente a la búsqueda de votos que el presidente no tiene capacidad de captar, y se trataría de una proporción considerable del apoyo electoral de la fórmula. En este sentido, por lo tanto, parece adecuado identificar tales votos con la legitimidad propia del vicepresidente.

Finalmente, la experiencia reciente de uno de los países aquí tratados -Argentina- obliga a reconsiderar la idea de la legitimidad vicepresidencial como inherentemente menor a la presidencial. En mayo de 2019, Cristina Fernández de Kirchner se postuló como candidata a la vicepresidencia, invirtiendo el proceso de selección habitual: fue ella quien nominó a Alberto Fernández como compañero de fórmula y candidato a la presidencia. Se desprendía de ello que la legitimidad y la atracción de votos residía principalmente en la candidata a la vicepresidencia. Puesto que esta fórmula ganó las elecciones de ese mismo año, se produjo por primera vez en América Latina -y posiblemente en el mundo- un caso que obliga a reelaborar la teoría existente sobre la legitimidad vicepresidencial.

\section{Estados UnIDOS}

Como se ha indicado antes, la vicepresidencia de Estados Unidos ha sido estudiada en mucho mayor profundidad y extensión que la de los países latinoamericanos, tanto desde la academia como desde la propia política. Esto ha llevado a que algunos de sus principales problemas fueran

23 A. Pignataro y M. Taylor-Robinson, "Party competition, gender quotas, and enhanced inclusiveness in the selection of vice-presidential candidates", Politics, Groups, and Identities, 9,4 (2021), pp. 721-738. 
paliados mediante leyes complementarias y enmiendas a la Constitución.

La primera de ellas, la Ley de Sucesión de 1792, situaba al presidente pro tempore del Senado y luego al presidente de la Cámara Baja en la línea sucesoria, ${ }^{24}$ pero también preveía una elección especial, convocada por el Secretario de Estado, en caso de doble vacancia (de presidente y vicepresidente).$^{25}$

La XII Enmienda a la Constitución ${ }^{26}$ estadounidense, de 1804, supuso un duro golpe para la reputación de la vicepresidencia. Según esta modificación, en lugar de obtener la primera magistratura -como hasta entonces- el candidato a presidente con mayor votación, y el que tuviera la segunda mayor votación, la vicepresidencia, los electores emitían dos votos distintos: uno para presidente y uno para vicepresidente. Eso significó que quien acababa ocupando la vicepresidencia no era un ciudadano con categoría de presidente: nadie que la tuviera se rebajaría presentándose como candidato a un cargo tan insignificante. En consecuencia, quienes competían por el puesto eran políticos de segunda o tercera línea: los únicos para los cuales la oscura vicepresidencia suponía alguna clase de incentivo. Hasta tal punto se percibía la degradación de la vicepresidencia bajo esta Enmienda, que fueron numerosas las voces que abogaron por su supresión. ${ }^{27}$

Resulta esencial remarcar que los cambios operados en la vicepresidencia estadounidense, por los cuales los vicepresidentes han ido ganando poder y funciones a lo largo de los últimos dos siglos, han aparecido progresivamente y de facto en virtud de las necesidades de la dinámica política; no ha

${ }^{24}$ United States Senate, "Presidential Succession", 20 de febrero de 1972, https://www.senate.gov/artandhistory/history/minute/Presidenti al_Succession.htm (consulta del 14 de febrero de 2019).

${ }^{25}$ J. Feerick, "Presidential Succession and Inability: Before and After the Twenty-Fifth Amendment", Fordham Law Review, 79, 3 (2011), 947.

26 S. Levinson, "The Twelfth Ammendment", Interactive Constitution, National Constitution Center, s/f, https://constitutioncenter.org/ interactive-constitution/amendments/amendment-xii

27 Goldstein, op. cit, p. 6. 
habido, al menos a este respecto, cambios en las reglas del juego. Esto es que, aunque este detalle suele pasar desapercibido, los miembros del Colegio electoral siguen votando en la actualidad por el presidente y por el vicepresidente de manera separada, mediante dos votos distintos. ${ }^{28}$

¿Podría darse, por lo tanto, que los miembros del Colegio electoral votaran por un presidente y un vicepresidente de partidos distintos? En efecto podría ocurrir y ha ocurrido, pero en casos muy marginales y, normalmente, como protesta contra el sistema de Colegio electoral (o contra alguna otra característica del sistema electoral), no como voto con auténtica voluntad de favorecer a un candidato con posibilidades de ganar. En las elecciones de 2016, por ejemplo, siete electores rompieron su pledge (compromiso con el partido que los había postulado). En algún caso votaron por otros miembros del mismo partido, pero en la mayoría lo hicieron por miembros de otros partidos ( $c f r$. Neale). Además, una importante proporción de estados tienen mecanismos que obligan a los electores a votar por los candidatos del partido que los ha postulado, so pena de anular su voto, forzarlos a rectificar y/o sancionarlos con multas. ${ }^{29}$

Ahora bien, en términos estrictos de representación, es necesario considerar que la XII Enmienda suponía una mejora, al menos desde una perspectiva normativa: implicaba que el vicepresidente realmente había sido elegido de manera individualizada y no había llegado al cargo como una especie de mochila del presidente. No obstante, a esa dimensión formal es necesario superponerle el plano de la costumbre y el de las normas complementarias. En este sentido, la vigencia de la XII Enmienda en la actualidad tiene su contrapeso, primero, en el sistema de fórmula o ticket, por el cual los candidatos

28 T. Neale, The Electoral College: How It Works in Contemporary Presidential Elections, CRs Report RL32611, Congressional Research Service, 2017, p. 9.

29 "Four state electors to be fined $\$ 1,000$ for vote", Kitsap Sun, 23 de diciembre de 2016, https:/ / eu.kitsapsun.com/story/news/2016/12/23/ four-state-electors-fined-1000-vote/95796628 (consulta del 12 de febrero de 2019). 
a presidente y vicepresidente se presentan juntos a las elecciones; y, segundo, por la tradición en algunos estados, y la existencia de derecho positivo en otros, que vinculan a los miembros del Colegio electoral a su pledge.

De todo lo anterior se deriva que el vicepresidente acaba siendo elegido como anexo del presidente, más allá de los matices y sutilezas consuetudinarios y normativos mencionados. Y que, por lo tanto, el grado en que representa a la ciudadanía puede ser puesto en tela de juicio. No es un dato menor el hecho de que hoy en día, en Estados Unidos, el candidato a gobernador de cada estado y su vicepresidente se eligen por separado, y este mecanismo es considerado por muchos expertos como una opción interesante para reformar el sistema de elección presidencial, volviendo a emitir el elector votos separados para presidente y vicepresidente, ${ }^{30}$ como se hizo a partir de 1804.

Lo anterior suscita un interesante dilema entre representatividad y relación presidente-vicepresidente: si hay un doble voto que permite elegir a candidatos de partidos diferentes, la representatividad es máxima, pero también crecen las probabilidades de una relación de desconfianza entre un presidente y un vicepresidente que no fue elegido por el primero, que puede pertenecer a un partido distinto, que puede proponer programas radicalmente diferentes, que no le debe lealtad personal alguna (en cuanto a la lealtad institucional, como se expone en este artículo, la situación es muy diferente en Estados Unidos y en América Latina). Por el contrario, si se utiliza el método de fórmula o ticket presidente-vicepresidente, el riesgo de pérdida de representatividad del vicepresidente se incrementa, pero se facilita la relación de lealtad y confianza entre ambos. ${ }^{31}$

Esta observación, más sencilla (al menos en apariencia) en el sistema bipartidista y estable de Estados Unidos, se vuelve más compleja en América Latina, donde la inestabilidad

${ }^{30}$ Levinson, art. cit.

${ }^{31}$ Marsteintredet, art. cit., p. 122. 
del sistema de partidos alimenta las probabilidades de alianzas interpartidistas en la fórmula presidente-vicepresidente; de manera que, aun sin elegir a presidente y vicepresidente por separado, es relativamente fácil ver a un presidente de un partido y un vicepresidente de otro conviviendo en el Ejecutivo, como ocurrió en los casos aquí analizados de Fernández y Cobos en Argentina, y Rousseff y Temer en Brasil. ${ }^{32}$

En 1886 se aprobó una nueva Presidential Succession Act que, ante la doble vacancia de presidencia y vicepresidencia, depositaba el Ejecutivo en un miembro del gabinete presidencial hasta que el presidente o el vicepresidente fueran rehabilitados, o hasta que se celebraran nuevas elecciones. Con este mecanismo se procuraba una sucesión automática, aun a falta de vicepresidente, presidente pro tempore del Senado y presidente (Speaker) de la Cámara alta, ${ }^{33}$ y se intentaba eliminar la posibilidad de que los poderes presidenciales recayeran en un representante del partido de oposición, en caso de que la Cámara alta no estuviese en manos del oficialismo. ${ }^{34}$ Sin embargo, esta ley implicaba que el sucesor no sería elegido por el pueblo, sino que sería nombrado de forma directa por el presidente. De manera que nuevamente aparece aquí el problema de la representación democrática. Esta normativa $-\mathrm{y}$ el problema representativo aparejado- quedarían fuera de vigor con la aprobación en 1947 de una nueva Presidential Succession Act.

Pero poco después, la xxv Enmienda constitucional recuperaría la posibilidad de que el vicepresidente, y por lo tanto el eventual presidente, fuera escogido por designación y no por voto popular. Esto es, que volviera a ponerse en duda su

${ }^{32}$ Para un análisis detallado de estas coaliciones véase Serrafero, art. cit.

${ }^{33}$ La vacancia de la presidencia en tiempos en que no había presidente del Senado ni presidente pro tempore de esa Cámara, aunque pueda parecer una situación extrema e improbable, se dio en efecto en 1881, y otra circunstancia muy similar se produjo apenas cuatro años más tarde, véase Schlesinger, art. cit., p. 496.

${ }^{34}$ Loc. cit. 
carácter representativo. En efecto, esta Enmienda, aprobada en 1967, autoriza al presidente a nombrar un nuevo vicepresidente si el cargo queda vacante, confirmando así el principio de designación en desmedro del principio electivo que se había asociado siempre al espíritu de la Constitución y a las propuestas de los padres fundadores de la nación.

Esta última modificación constitucional dio lugar, en 1976, a la presencia simultánea de un presidente y un vicepresidente no elegidos, ninguno de los dos, por el voto popular, sino designados en virtud de la enmienda de 1967. Así, en 1973 presentó su renuncia Spiro Agnew, vicepresidente de Richard Nixon, ante lo cual el presidente designó a Gerald Ford como vicepresidente sustituto. Luego, la renuncia de Nixon hizo subir a la primera magistratura al propio Ford, que por la XXv enmienda se vio obligado a designar a un vicepresidente; el elegido fue Nelson Rockefeller. Así, tanto Ford (presidente) como Rockefeller (vicepresidente) habían sido designados discrecionalmente; ninguno de los dos había llegado al poder mediante comicios. ${ }^{35}$

Antes de pasar a los casos argentino y brasileño, hay un elemento más que es importante tener en consideración para el caso de Estados Unidos: los dos cambios operados en el tiempo en relación con la selección del candidato a vicepresidente. En primer lugar, a partir de 1828, tal designación pasó de las manos de un pequeño grupo de líderes partidarios a las de la convención partidaria, y los candidatos presidenciales no tenían voz ni voto en la selección de su compañero de fórmula. ${ }^{36}$ Es decir que la elección del candidato a vicepresidente ganaba en poder representativo, en tanto era fruto de una deliberación entre representantes de todo el país. A partir de los años sesenta del siglo xx se produjo el segundo cambio: viraje radical mediante la cual la elección del vicepresidente dejó de estar a cargo de los delegados del partido y pasó que el candidato a presidente la

35 Loc. cit.

${ }^{36}$ Baumgartner, op. cit., p. 17. 
efectuara, sin siquiera consultar con la convención partidaria. ${ }^{37} \mathrm{El}$ procedimiento anterior concedía a los miembros del partido de todo el país una representación que desaparece con el nuevo sistema. El hecho de que en la actualidad el partido se limite a avalar al candidato a vicepresidente elegido por el candidato a presidente implica un desequilibrio en el sentido ya mencionado: mayor lealtad personal presidente-vicepresidente, pero menor representatividad.

En conclusión, en Estados Unidos parece poco probable -al menos hasta este momento- que se produzcan los enfrentamientos entre presidente y vicepresidente que, como se verá a continuación, ocurren con cierta frecuencia en América Latina. Es decir que con dificultad surgirá un déficit de representatividad democrática derivado de un distanciamiento entre los dos miembros del Ejecutivo, diferenciándose el vicepresidente de la persona, el programa, las ideas y, en consecuencia, de los votantes y la representación democrática del presidente. Aun así, las normas referidas a la vicepresidencia estadounidense dejan abierto un flanco por el cual puede colarse un problema de representación.

\section{AmÉrica Latina}

El proceso constituyente de Estados Unidos ejerció una clara influencia en la formación de repúblicas presidencialistas entre los países latinoamericanos que se independizaron de sus respectivas metrópolis a principios del siglo xIx. De un análisis de esas constituciones latinoamericanas se desprende que la mayor parte de los países de la región ha adoptado la figura del vicepresidente. Sin embargo, no sólo se registran diferencias en el número de éstos y en las posiciones que ocupan en el entramado del gobierno, sino que ni siquiera

${ }^{37}$ Ibid., p. 58. 
en todos los casos cumple la función originaria de sucesor presidencial. $^{38}$

De 19 países, 13 incorporaron en sus constituciones la figura de un vicepresidente. De esos, cuatro establecen la sucesión presidencial como único fin de este cargo (Bolivia, República Dominicana, El Salvador y Honduras); en otros tres: Colombia, Ecuador y Nicaragua, además de su función de sucesión, el vicepresidente desempeña -según la Constitución- las actividades que el presidente le delegue; las constituciones de Guatemala, Paraguay y Venezuela determinan que el vicepresidente sucederá al presidente cuando sea necesario, además de llevar a cabo una serie de funciones establecidas en el propio texto constitucional y las que el presidente le asigne. En Uruguay el vicepresidente es presidente de la Asamblea General y del Senado. Finalmente, en el caso de Brasil, el vicepresidente debe auxiliar al presidente cuando éste lo disponga y se le pueden asignar otras responsabilidades por ley complementaria.

En tres de los seis países restantes, Costa Rica, Panamá y Perú, hay -en cada uno- dos vicepresidentes. En el caso de Panamá, ambos sucesores tienen ciertas responsabilidades asignadas por el propio texto constitucional; en los otros dos países, la única función establecida por la Constitución es la de reemplazar al presidente en los casos en que corresponda.

Chile y México, por su parte, no cuentan con esta figura. En Chile, el mecanismo para suplir al presidente ante una eventual muerte, renuncia o inhabilidad para ejercer sus funciones coloca primero en el orden de sucesión al presidente del Senado, seguido por el presidente de la Cámara de Diputados y, en tercer lugar, por el presidente de la Corte Suprema de Justicia; no obstante, éstos asumen la pri-

${ }^{38} \mathrm{Si}$ bien se trata de un caso excepcional, se verá que la Constitución venezolana de 2007 incorpora un vicepresidente ejecutivo como parte activa del equipo de gobierno, aunque sólo en determinadas circunstancias esa figura ocupa la presidencia en reemplazo del titular. 
mera magistratura con el título de vicepresidente. En México, en cambio, el Congreso (o la Comisión Permanente, si éste no se encuentra en sesiones) nombra a un presidente provisional para completar el respectivo periodo.

Resulta interesante contrastar los países cuyo vicepresidente preside el Senado con el caso de Chile, en donde el presidente del Senado es convocado a suceder al presidente de la República cuando así se requiere. Este contraste trae reminiscencias de la máxima latina quia magis dignum trahit ad se minus dignum: ${ }^{39}$ la causa mayor absorbe a la menor. Es decir que, en países como Argentina, la sucesión presidencial constituiría la causa mayor, a la que se anexaría la presidencia del Senado; mientras que en Chile la presidencia del Senado sería la causa mayor, que absorbería la función sucesoria, esto es, la causa menor. Esta misma lógica predomina en Estados Unidos, en donde la elección presidencial, causa mayor, habría absorbido a la función sucesoria, causa menor. Esta apreciación no deja de aportar cierta luz sobre la exigua importancia concedida a la sucesión durante la constitución política de algunos países.

Para completar esta breve mirada a los países latinoamericanos, la Constitución cubana establece la existencia de un primer vicepresidente y cinco vicepresidentes; éstos pueden desempeñar algunas tareas si el presidente así lo dispone, mientras que la principal misión del primer vicepresidente es reemplazar al presidente en caso de ausencia, enfermedad o muerte.

El cuadro 1 resume la diversidad constitucional latinoamericana respecto a la figura vicepresidencial.

39 Máxima citada por E. Plowden, Commentaries, or Reports, Londres, S. Brooke, $(1816,1571)$, p. 213a. Edmund Plowden era, por cierto, una de las máximas autoridades de su tiempo (el siglo xvi) en lo que a la sucesión de la Corona inglesa se refería. 


\section{CUADro 1}

\section{La vicepresidencia en las constituciones latinoamericanas}

\begin{tabular}{|c|c|c|c|}
\hline País & Vicepresidente(s) & Funciones & Clasificación \\
\hline Bolivia & Uno & Sucesión & Rígida \\
\hline Brasil & Uno & $\begin{array}{c}\text { Sucesión + auxilio del presidente cuando } \\
\text { éste lo disponga y otras funciones que le } \\
\text { sean asignadas por ley complementaria }\end{array}$ & Rígida \\
\hline Colombia & Uno & $\begin{array}{c}\text { Sucesión + funciones delegadas por el } \\
\text { presidente }\end{array}$ & Rígida \\
\hline $\begin{array}{l}\text { República } \\
\text { Dominicana }\end{array}$ & Uno & Sucesión & Semirrígida \\
\hline Ecuador & Uno & $\begin{array}{l}\text { Sucesión + funciones asignadas por el } \\
\text { presidente }\end{array}$ & Semirrígida \\
\hline El Salvador & Uno & Sucesión & Rígida \\
\hline Guatemala & Uno & $\begin{array}{c}\text { Sucesión }+ \text { funciones especificadas en la } \\
\text { Constitución }\end{array}$ & Semirrígida \\
\hline Honduras & Tres & Sucesión & Rígida \\
\hline Nicaragua & Uno & Sucesión & Rígida \\
\hline Paraguay & Uno & $\begin{array}{c}\text { Sucesión + funciones especificadas en la } \\
\text { Constitución + funciones delegadas por } \\
\text { el presidente }\end{array}$ & Rígida \\
\hline Uruguay & Uno & $\begin{array}{c}\text { Sucesión + presidencia de la Asamblea } \\
\text { General y del Senado }\end{array}$ & Rígida \\
\hline Venezuela & Uno & $\begin{array}{c}\text { Sucesión }+ \text { funciones especificadas en la } \\
\text { Constitución }+ \text { funciones delegadas por } \\
\text { el presidente }\end{array}$ & Elástica \\
\hline Costa Rica & Dos & Sucesión & Rígida \\
\hline Panamá & Dos & $\begin{array}{c}\text { Sucesión + responsabilidades } \\
\text { constitucionales }\end{array}$ & Rígida \\
\hline Perú & Dos & Sucesión & Rígida \\
\hline Cuba & $\begin{array}{c}\text { Un primer } \\
\text { vicepresidente y } \\
\text { cinco } \\
\text { vicepresidentes } \\
\end{array}$ & $\begin{array}{c}\text { Primer vicepresidente: sucesión; } \\
\text { vicepresidentes: tareas asignadas por el } \\
\text { presidente }\end{array}$ & $\begin{array}{l}\mathrm{n} / \mathrm{d} \\
\text { (régimen no } \\
\text { democrático) }\end{array}$ \\
\hline Chile & Ninguno & & \\
\hline México & Ninguno & & \\
\hline
\end{tabular}

Fuente: elaboración propia. 
Argentina

En 2007 asumió la presidencia argentina la peronista Cristina Fernández. La vicepresidencia fue el espacio utilizado para construir un gobierno de coalición, en el que se apuntó al radical Julio Cobos como vicepresidente. Cobos había sido subsecretario de Urbanismo y Vivienda a nivel municipal y gobernador de la provincia de Mendoza, siempre por el radicalismo. ${ }^{40}$

En el seno del Poder Ejecutivo, Cobos comenzó su mandato con algunas participaciones menores. ${ }^{41}$ Además, al igual que el anterior presidente, Néstor Kirchner, Cristina Fernández no organizaba reuniones de gabinete, ${ }^{42}$ de modo que Cobos, aún si su relación con la presidente hubiese sido buena, no habría tenido acceso a la información y las decisiones de mayor relevancia.

En el caso de Cobos, fue particularmente interesante el equilibrio de fuerzas a que llevó su filiación partidaria sui generis: por un lado, contó en principio con el apoyo del radicalismo K (radicales kirchneristas); por otro, fue objeto de presiones de estos mismos cuando Cristina Fernández comenzó a mostrar que no los incorporaría al gobierno ni a la toma de decisiones en la medida que ellos esperaban; en tercer lugar, el radicalismo "puro» lo vio como un traidor y emprendió acciones para debilitarlo. ${ }^{43}$ Esta sumatoria de fuerzas cambiaría sustancialmente tras el desempate del vicepresidente en el Senado, que se explicará a continuación.

Poco después de asumido el poder, llegó al Senado la batalla instalada entre el gobierno y el sector agropecuario por una propuesta de ley de retenciones a la exportación de determinadas commodities; tras una dura sesión en la que el

${ }^{40}$ Castro, op. cit., p. 393.

41 Ibid. p. 398.

42 Entrevista del autor a un alto cargo del Senado argentino que solicitó permanecer en el anonimato.

43 "Radicales K pidieron más participación”, La Nación, 15 de abril de 2008. 
presidente del cuerpo debió usar su voto de desempate, ${ }^{44}$ Cobos rechazó el proyecto legislativo del gobierno. A partir de entonces, la ruptura entre presidenta y vicepresidente fue taxativa: el segundo se transformó en un opositor abierto, pero radicado en el propio Ejecutivo. Cobos sumó el apoyo de numerosos sectores opuestos al gobierno y comenzó a revisarse su expulsión de la UCR. ${ }^{45}$ Por último, la expansión de su liderazgo, la creación de un partido político bajo su conducción y el surgimiento de un sector de kirchneristas desencantados le significaron la incorporación de apoyos políticos sustanciales.

No obstante, si seguimos la premisa de que los electores votaron por la fórmula Fernández-Cobos fundamentalmente por la primera, y de modo muy marginal por el candidato a vicepresidente, es necesario preguntarse en qué medida la idea de representación democrática quedó truncada en lo que respecta al segundo. Por lo mismo que la comunidad académica no ha prestado hasta ahora dedicación suficiente a la vicepresidencia, las encuestas sobre asuntos políticos no recogen -en país alguno- con suficiente detalle las opiniones de la población sobre este cargo. Es imposible al día de hoy saber qué esperan los ciudadanos de un vicepresidente: protagonismo o perfil bajo; lealtad absoluta o contrapeso al presidente; actividad intensa o quietud máxima. Y, por supuesto, tampoco se sabe qué parte de la población estaría a favor de eliminar este cargo y qué proporción lo considera imprescindible.

Sin embargo, el hecho de que los candidatos a presidente dediquen mucho esfuerzo y negociaciones a elegir cuidadosamente a su candidato a vicepresidente permite inferir que el cargo tiene algún grado de importancia, al menos a la hora de las elecciones. Es decir, que alguna parte de la población tiene en cuenta quién es el candidato a vicepresidente cuando

${ }^{44}$ Era la primera vez que un vicepresidente de la nación utilizaba este recurso desde la reinstauración democrática.

${ }^{45}$ La resolución aparece en Castro, op. cit., p. 396. 
elige a su candidato a presidente. Y si bien, como se señalaba anteriormente, la falta de datos demoscópicos imposibilita saber exactamente qué perfil de vicepresidente prefiere la mayor parte de la población, es posible asumir que, aún si se decantan por un vicepresidente con protagonismo, con actividad intensa y que ejerza de contrapeso al presidente, se tratará de un vicepresidente leal (si no a la persona, al menos a la institución presidencial), que no haga oposición destructiva desde dentro del Ejecutivo, que forme equipo con el presidente, más allá de las posibles discrepancias.

Por otro lado, pese a la mencionada falta de estudios demoscópicos sobre las actitudes de la ciudadanía hacia la vicepresidencia en general y hacia Julio Cobos en particular, las numerosas muestras de animadversión a éste confirman en buena medida que el vínculo de representación efectivamente se había roto. En este sentido, pueden mencionarse escraches, pintadas de "traidor" en la casa del vicepresidente ${ }^{46} \mathrm{y}$ hasta la convocatoria de marchas exigiendo su renuncia. ${ }^{47}$

Esa renuncia nunca llegó, ni la presidente Fernández tuvo a su alcance mecanismo alguno para forzarla. En consecuencia, Julio Cobos se mantuvo como opositor en el seno del Ejecutivo argentino durante casi la totalidad del mandato (desde julio de 2008 hasta diciembre de 2011), dando lugar a una situación extremadamente polémica en lo que respecta a la representación.

Ahora bien, la conflictiva presidencia de Cobos, además de algunas respuestas, genera interrogantes clave. En una entrevista del autor, en 2019, al preguntar por los motivos que lo llevaron a no renunciar pese al conflicto abierto con la presidente, el exvicepresidente afirmó: "Tenía una obligación institucional con el pueblo, con los que me votaron y los

46 "Escrachan a Cobos en su casa", La Nación, 18 de julio de 2008, https:/ / www.lanacion.com.ar/1031537-escrachan-a-cobos-en-su-casa (consulta del 21 de febrero de 2019).

47 "K y sus grupos convocan a la plaza para echar a Cobos", Río Negro, 22deabrilde2010,https:/ / www.rionegro.com.ar/k-y-sus-grupos-convocana-la-plaza-para-echar-FXRN_353204 (consulta del 21 de febrero de 2019). 
que no". ${ }^{48}$ En el marco de esta investigación sobre el carácter representativo de la vicepresidencia resulta obligatorio plantearse: ¿cómo se reconfigura la relación representativa ante un Ejecutivo dividido? ¿A qué parte de la ciudadanía está vinculado el vicepresidente normativa, política y moralmente? ¿Es compatible el ejercicio del cargo con la genuina representación de los intereses de ese sector? Estas respuestas se suman a muchas otras acerca de los aspectos normativos de la vicepresidencia que aún no tienen respuesta, y que forman parte de la extensa agenda de investigación que está pendiente de desarrollo en torno a esta institución.

\section{Brasil}

El caso de Michel Temer es especialmente interesante debido a que llegó a la presidencia de Brasil con un índice de popularidad insólitamente bajo: un $14 \% .{ }^{49}$ Si bien podría debatirse largamente acerca de las diferencias entre índice de popularidad, legitimidad y representatividad democrática, la proximidad entre estos tres conceptos es indudable, y quien ostenta un índice de popularidad de $14 \%$ difícilmente podrá presumir de representar la voluntad mayoritaria de la nación.

Lo complejo de esta situación proviene, precisamente, de que ese bajísimo índice de popularidad es perfectamente compatible con un seguimiento estricto de los cauces democráticos establecidos en las leyes. ¿Se puede decir, entonces, que las previsiones constitucionales brasileñas facilitan el acceso al poder de vicepresidentes que representan en un grado extremadamente bajo a la nación que votó por ellos?

Rousseff y Temer, igual que Fernández y Cobos en Argentina, habían concurrido en coalición a las elecciones de 2010

${ }^{48}$ Entrevista inédita, 5 de junio de 2019.

49 A. Jiménez Barca, "Temer busca capear su profunda impopularidad", El País, 5 de agosto de 2016. 
y 2014, ganando ambos comicios. Rousseff era candidata por el Partido de los Trabajadores, y Temer lideraba el Partido do Movimento Democrático de Brasil. El primer mandato de ambos (2011-2014) transcurrió sin incidentes. Sin embargo, durante el segundo mandato (2015-2018) se abrió el proceso de impeachment contra la presidenta, en el cual el vicepresidente tuvo un papel destacado: por un lado, el partido que lideraba abandonó oficialmente el Ejecutivo, retirando su apoyo y aislando a Rousseff. ${ }^{50}$ Por otro lado, el propio Temer filtró -alegadamente por error- mensajes por distintos medios que lo presentaban con certeza como presidente antes de serlo, al tiempo que exponían a Rousseff como cadáver político antes de que se materializara el impeachmenty su consecuente alejamiento de la primera magistratura. De ahí que la misma Rousseff lo acusara de golpista y de encabezar la conspiración que la hizo caer. ${ }^{51}$

La llegada de Temer al poder el 31 de agosto de 2016 confirmó el cambio de rumbo que tomaba el país, comenzando un bienio marcadamente más conservador en todos los ámbitos. Es decir, que se implementaba a partir de entonces un programa de gobierno indudablemente distinto del que había propuesto Rousseff; esto es, indudablemente distinto del que había obtenido el respaldo mayoritario en las elecciones.

Las diferencias con el caso argentino, es decir, las particularidades que aparecen cuando el vicepresidente-opositor llega a la presidencia, son evidentes. Mientras que Julio Cobos, aún después de ganar el respaldo de gran parte de la oposición al gobierno de Fernández, seguía siendo solamente el vicepresidente, y por tanto podía obstaculizar en pequeña medida pero no podía frenar los planes de la presidente ni marcarle al gobierno un camino distinto del comprometido por Fernández con los votantes, Temer sí pudo hacerlo, y

50 A. Jiménez Barca, "El partido aliado de Rousseff deja el Gobierno y aísla a la presidenta todavía más”, El País, 30 de marzo de 2016.

${ }^{51}$ A. Jiménez Barca, "El vicepresidente brasileño Michel Temer se ve ya como presidente", El País, 12 de abril de 2016. 
lo hizo. Así lo recogieron estudios académicos como Feliú, ${ }^{52}$ que da cuenta de la reforma laboral, la ley de terciarización y las concesiones públicas al sector privado; y también medios de comunicación como The New York Times: "La agenda del Sr. Temer, que ha incluido una revisión de las leyes laborales que ha debilitado a los sindicatos, ha llevado a los críticos a acusarlo de usurpar la voluntad de los votantes que eligieron a la Sra. Rousseff, izquierdista". ${ }^{53}$

Casi 30 años antes de la asunción de Temer, en el alba de la restauración democrática, Brasil había vivido ya un episodio de dudosa legitimidad vicepresidencial. El primer presidente electo de la democracia, Tancredo Neves, se indispuso unas horas antes de asumir el cargo, por lo que éste quedó en manos de su vicepresidente, José Sarney. Leal al ejército y miembro del partido ARENA durante la dictadura (1964-1988), la llegada de Sarney al poder hizo sonar las alarmas en todos los sectores comprometidos con la reinstauración democrática. Sarney tuvo que dar muestras extraordinarias de compromiso con la democracia y con la agenda de derechos sociales para sobreponerse a la desconfianza y la escasa legitimidad con que había asumido la presidencia. "Invertir en instituciones participativas se convirtió en la manera simbólica en la que el gobierno de Sarney apaciguó a los grupos del movimiento democratizador, y demostró así su compromiso con las metas compartidas de los derechos sociales. Simplemente, hacer concesiones a los grupos individuales de la sociedad civil no le habría aportado el mismo grado de legitimidad". ${ }^{54}$

${ }^{52}$ P. Feliú, "Sobreviviendo a reformas, impopularidad y casos de corrupción: el presidencialismo de coalición del Brasil de Temer”, Revista de Ciencia Política, 38 (2) (2018), pp. 181-206.

53 M. Andreoni, "Michel Temer, Brazil's Deeply Unpopular President, Signals Run for a New Term", The New York Times, 24 de marzo de 2018. [Traducción de la editora].

${ }^{54}$ L. R. Mayka, "Bringing the Public into Policymaking: National Participatory Institutions in Latin America", tesis doctoral, Berkeley, University of California, 2013, pp. 38-39. [Traducción de la editora]. 
Apenas cuatro años después, el presidente brasileño Fernando Collor de Mello fue sometido a juicio político por corrupción, y renunció durante el proceso de impeachment, dejando la presidencia en manos de su vicepresidente, Itamar Franco. Hasta tal punto eran palpables las diferencias entre uno y otro, que autores como Weyland afirman que Franco era una buena alternativa para los opositores a Collor que lideraron el juicio político, mientras que buena parte de los seguidores del destituido presidente se sentían renuentes a la figura de Franco. Finalmente, para asegurarse la viabilidad política de su acceso al poder, Franco tuvo que asegurar a determinados sectores que no cambiaría drásticamente el rumbo tomado por Collor. ${ }^{55}$

La experiencia brasileña en conjunto muestra que la amenaza de la vicepresidencia a la representatividad democrática presenta diversos grados y matices; no se trata de la presencia o la desaparición absolutas de la capacidad representativa. Mientras que en el caso de Itamar Franco se advierten tonos suaves de déficit representativo, manifestados en la diferencia entre su programa y el del presidente al que reemplazaba, así como en la desconfianza hacia el vicepresidente de algunos sectores que habían apoyado al titular (sectores influyentes pero no mayoritarios, puesto que se trataba fundamentalmente de élites productivas, no del apoyo al vicepresidente entre las bases ciudadanas), en el caso de Michel Temer, en cambio, tal déficit alcanza su grado máximo: se produce un sensible cambio en el programa de gobierno y el vicepresidente llega a la presidencia con un grado de aceptación popular insólitamente bajo.

55 K. Weyland, The Politics of Market Reform in Fragile Democracies: Argentina, Brazil, Peru, and Venezuela, Princeton, University Press, 2002, p. 212. 


\section{UNA PERSPECTIVA COMPARATIVA: PRESIDENCIALISMOS SIN VICEPRESIDENTE Y PARLAMENTARISMO}

Para una mejor comprensión del asunto que aquí se trata es útil tener en cuenta cómo funcionan los sistemas presidenciales sin vicepresidencia y los parlamentarismos frente a circunstancias como las aquí analizadas.

En primer lugar, para todos los casos vale una premisa que establece una diferencia básica: al no elegirse presidente $\mathrm{y}$ vicepresidente en fórmula o ticket, no hay un vicepresidente fijo, por lo que no pueden darse deslealtades de manera continuada. Naturalmente, se pueden construir alianzas electorales y de gobierno basadas en un presidente de un partido y un vicepresidente de otro; y las relaciones entre éstos pueden deteriorarse una vez en el gobierno. Esto ocurre con cierta frecuencia en sistemas parlamentarios. No obstante, en estos casos, el rumbo natural es la ruptura de la alianza o la sustitución del vicepresidente. Lo que no tiene posibilidades prácticas es que continúen en el Ejecutivo un presidente y un vicepresidente en colisión sistemática, a diferencia de lo que ocurre en los países con vicepresidencia fija, donde el presidente no se puede deshacer del vicepresidente. Ni qué decir de los países sin vicepresidente, como Chile o México. Como sea, lo que se verifica es que ni en presidencialismos sin vicepresidencia fija ni en parlamentarismos se mantiene en el cargo un vicepresidente opositor al jefe del Ejecutivo que representa -idealmente- la voluntad popular.

Por otro lado, es interesante notar que, en algunos países con sistema parlamentario, como el caso de España, no es requisito que el presidente del gobierno ni los ministros de su gabinete, entre los que se cuenta el vicepresidente (si lo hay), sean diputados; es decir, que hayan sido elegidos por los ciudadanos. Es lo habitual, no obstante, que el presidente lo sea. ${ }^{56}$ De manera que el caso ocurrido en Estados Unidos, en

${ }^{56} \mathrm{~J}$. Vintró, "El rey y la investidura del presidente del gobierno", Agenda Pública / El País, 21 de enero de 2016. 
1976, tiene su paralelo en algunos sistemas parlamentarios: en ambos puede darse que el presidente y el vicepresidente no hayan sido directamente elegidos por la vía electoral, pero en ambos esto supone una anomalía y una excepción. Es importante remarcar, no obstante, que mientras en España esta circunstancia no estaría específicamente vinculada con la vicepresidencia, en Estados Unidos sí lo está: es la necesidad de cubrir la vacante vicepresidencial la que activa este mecanismo.

Además, la lógica parlamentaria introduce más matices diferenciales. En países con esta forma de gobierno, la ruptura de una alianza de gobierno lleva casi con certeza a la caída del mismo (implique esto disolución de las Cortes o no; puede simplemente formarse un nuevo gobierno): si había alianza es porque ninguno de los partidos del Ejecutivo tenía mayoría para gobernar. Por lo tanto, rota la coalición, ninguno de ellos puede seguir gobernando solo, y el gobierno cae. El nuevo gobierno que se forme seguirá representando a los votantes. La figura del vicepresidente irremovible y elegido en ticket con el presidente es la que introduce la posibilidad de que el jefe del Ejecutivo tenga mínimo respaldo popular. En cambio, la ruptura de la alianza presidente-vicepresidente en un presidencialismo no implica nada de eso: pueden seguir presidente y vicepresidente en el gobierno, pero en relación de tensión o enfrentamiento abierto. ${ }^{57}$

$\mathrm{Al}$ abordar los problemas de legitimidad y lealtad, Marsteintredet sugiere que su fuente no es la vicepresidencia misma, sino "cómo se construye el sistema de sucesión". ${ }^{58}$ Es decir, se queda en el ámbito de las instituciones, de las reglas, y no entra en el un terreno más pantanoso pero también más interesante y más abundante en respuestas: el de la cultura política. Así, este autor pasa por alto que con las mismas reglas del juego, que en gran parte de América Latina

${ }^{57}$ Para una tipología de relaciones presidente-vicepresidente, véase Sribman, 2011, art. cit.

${ }^{58}$ Marsteintredet, art. cit., p. 126. 
han demostrado la imposibilidad de generar lealtad entre presidente y vicepresidente, en Estados Unidos tal lealtad resulta incontestable, y la estabilidad en el seno del Ejecutivo es consecuentemente indiscutible. En este mismo sentido deja Marsteintredet fuera del análisis varios matices ya mencionados y que apuntan precisamente a la construcción del sistema de sucesión: en primer lugar, tanto en Estados Unidos como en Brasil y Argentina (y buena parte de América Latina) es el candidato a presidente quien elige a su running mate; la diferencia fundamental radica, como se ha mencionado, en la cultura política: en Estados Unidos sería impensable un enfrentamiento entre presidente y vicepresidente, no porque provengan del mismo partido, sino porque la lealtad a las instituciones es mucho más fuerte. ${ }^{59}$ En efecto, cuando se produjeron enfrentamientos entre presidente y vicepresidente en países latinoamericanos, la desestabilización del Ejecutivo fue indudable (en el propio artículo de Marsteintredet pueden consultarse ejemplos), pero ello no fue motivo suficiente para que se pusiera fin inmediato al enfrentamiento.

En segundo lugar, en Estados Unidos, los miembros del Colegio electoral votan por separado a presidente y vicepresidente. Si bien a veces se producen los ya mencionados casos de faithless electors, que no votan por el candidato encomendado por el partido al que representan, esta opción es absolutamente marginal. Nuevamente vemos aquí el peso de la cultura política: aun cuando -como el caso de Donald Trump en las últimas elecciones- el candidato no es del agrado de muchos electores de su partido, la lealtad institucional los impele a votar por él y no desviar el mandato partidario.

En tercer lugar, los partidos pueden desarrollar recursos para corregir algunos mecanismos inconvenientes de las instituciones. Por ejemplo, como también se ha indicado antes, algunos partidos estadounidenses a nivel estatal pueden penalizar al miembro del Colegio electoral que no ha seguido

${ }^{59}$ Sribman, 2011, art. cit. 
su pledge, anular su voto u obligarlo a rectificar. De esta manera, no todo el comportamiento de los actores políticos está guiado por las normas constitucionales y leyes aledañas, sino que algunas directrices propias los circunscriben aún más.

\section{Conclusiones}

La vicepresidencia de corte estadounidense plantea numerosos problemas a los sistemas políticos que la han adoptado. Este trabajo se ha centrado en uno de particular relevancia: la amenaza que supone por diversas vías para el carácter representativo de la democracia.

A partir de tres casos, Estados Unidos, Argentina y Brasil, se ha dado cuenta de cómo este cargo conduce, por diversas vías, a situaciones en las que el Ejecutivo en conjunto o uno de sus componentes presentan un importante déficit de representatividad. En casos que no resultan excepcionales, la vicepresidencia puede poner el gobierno en manos de un magistrado que no tenga la legitimidad representativa derivada de las elecciones. Aun sin llegar a la presidencia, el vicepresidente-que recibió el voto de los ciudadanos como parte de un equipo junto al presidente- puede transformarse en opositor, sin posibilidades de que se le destituya $y$, de esta manera, poner en cuestión el sentido último de ese voto.

Estas características verificadas empíricamente chocan con los rasgos atribuidos al Ejecutivo en el papel: es imprescindible que éste represente la soberanía popular, también cuando queda en manos del vicepresidente, puesto que ya no es -como pudo considerarlo Tocqueville hace 200 años- un mero ejecutor de las leyes emanadas del Legislativo. El carácter personalizado e hiperpresidencial de la política actual en las Américas obliga a reconsiderar la naturaleza del Ejecutivo y, por lo tanto, el mayor o menor ajuste entre las normas y el desempeño real de las instituciones. 
La forma de postulación del vicepresidente presenta numerosos problemas en este sentido: en Estados Unidos se ha ido estableciendo su designación por el candidato a presidente, sin intervención real del partido reunido en asamblea; es decir, prescindiendo de lo que podría ser un primer paso de representación federal: la convención de los representantes de todo el país para cada partido. En América Latina, por otra parte, es muy habitual la utilización de la fórmula presidente-vicepresidente para crear alianzas interpartidistas que, una vez en el gobierno, son difíciles de sostener. Alianzas en las que, si se puede afirmar que el presidente representa la voluntad popular y el proyecto político vencedor en las urnas, resulta difícil afirmar lo mismo de un vicepresidente que ostenta, en muchos casos abiertamente, un ideario distinto -incluso opuesto- al de aquél.

Es decir que las candidaturas de alianza introducen un elemento disruptivo, que afecta la representación democrática: la eficacia electoral de una coalición no implica la genuina comunión de los programas y planteamientos políticos de las partes que la componen. Tanto en el caso argentino como en el brasileño se han presentado ejemplos de alianzas presidente-vicepresidente de partidos distintos, cuyas diferencias eclosionaron una vez la fórmula llegó al poder. En tales casos (Temer en Brasil, Cobos en Argentina) se hizo evidente el vaciamiento de la relación de representación ciudadanía-vicepresidente.

Además, en esos casos, el presidencialismo añade rigidez a la coyuntura política: mientras que en un sistema parlamentario una coalición de investidura puede no implicar coalición de gobierno, en un sistema presidencial una alianza electoral se transforma necesariamente en coalición de gobierno. En otras palabras, si un candidato a presidente de un partido gana las elecciones en coalición con un candidato a vicepresidente de otro partido, ineludiblemente llegarán al Ejecutivo juntos. Así, el vínculo tripartito entre vicepresidencia, presidencialismo y alianzas es categóricamente más rígido en los casos estudiados que en los sistemas 
parlamentarios. A su vez, esa rigidez, combinada con la indisponibilidad de la vicepresidencia, ${ }^{60}$ facilitan la ocurrencia de puntos muertos en el seno de la dupla ejecutiva.

¿Puede afirmarse que la elección conjunta de presidente y vicepresidente otorga igual -o similar- legitimidad a ambos? ¿Puede interpretarse que la legitimidad del presidente, derivada de las urnas, se transfiere automáticamente al vicepresidente? En este ámbito, la investigación realizada hasta la fecha se encuentra aún distante de ofrecer certezas. Mientras que los estudios sobre selección de candidatos y campanas electorales conceden a la vicepresidencia un lugar nada desdeñable, algunas teorías sostienen que la vicepresidencia, en su tendencia a la marginalidad, no goza de una legitimidad sustancial de origen. A modo de hipótesis tentativa se afirma aquí que este factor varía mucho entre países, entre campañas de un mismo país y entre fórmulas de una misma campaña.

Más allá de la elección, las normas relativas a la vicepresidencia crean nuevos inconvenientes en términos de representación: en Estados Unidos, donde la lealtad entre las dos cabezas del Ejecutivo no es fuente de disputas, puede sin embargo darse -y se ha dado- el caso de un presidente y un vicepresidente que no habían sido elegidos en las urnas, sino nombrados "a dedo". En América Latina, donde no existe -en ningún país- tal disposición, es; frecuente, en cambio, la tensión o incluso el enfrentamiento abierto entre presidente y vicepresidente. Y si el segundo llega a la presidencia, son altas las probabilidades de que imponga al Ejecutivo un cambio de rumbo notable, incluso radical, distanciándose así del ideario respaldado por la ciudadanía en las urnas.

Parece indudable que, más allá del programa de gobierno, el voto ciudadano está dirigido a la persona del presidente,

60 Ariel Sribman, "Los principios de disponibilidad e inmediatez en la vicepresidencia latinoamericana”, Res Publica. Revista de Historia de las Ideas Políticas, vol. 24, núm. 2, 2021, pp.161-172, https://doi.org/10.5209/ rpub. 70008 
a sus características individuales que concitan la confianza del votante. Por lo tanto, aun si un vicepresidente que asciende a la presidencia mantiene vigente el programa del titular, cabe dudar que la relación de representación ciudadanos-Ejecutivo se mantenga intacta. Pero sí cabe dudarlo mucho más si, además del cambio de persona, se produce un cambio de programa, como ocurrió en Brasil tras la destitución de Rousseff.

"La democracia es el peor sistema de gobierno, a excepción de todos los demás que se han probado”, afirmó Winston Churchill ante la Cámara de los Comunes británica el 11 de noviembre de 1947. ¿Puede decirse algo similar de la vicepresidencia? ¿Es el peor sistema sucesorio a excepción de todos los demás que alguna vez se intentaron? Para responder a esta pregunta es necesario evaluar la capacidad de otros métodos sucesorios para solventar la ausencia del jefe del Ejecutivo, evitando sin embargo el déficit representativo que aquí se asocia a la vicepresidencia. Tanto la vicepresidencia elástica (donde el presidente puede remover al vicepresidente) como las configuraciones políticas sin vicepresidente son ejemplos de ello. Se podría afirmar, en contra de este argumento, que el espíritu de este carácter elástico es precisamente el que llevó a adoptar la xxv Enmienda en Estados Unidos, que aquí se presenta como problemática en cuanto a la representación democrática. Sin embargo, existe un recurso que debe tenerse en cuenta y que atenuaría tal inconveniente: la prescripción constitucional de elecciones en un plazo, breve desde que el vicepresidente sustituye al presidente. Así ocurre en países como Francia o, con ciertos matices, en Chile. La figura que sustituye al presidente vacante (sea un vicepresidente por él nombrado, el presidente del Senado o de cualquier otro órgano) no permanece en el poder más que el tiempo suficiente para convocar a elecciones, y está además inhabilitado por la Constitución para tomar determinadas medidas (desde la designación o destitución de ciertos cargos hasta la implementación de determinadas políticas). 
Existe una íntima relación entre representatividad democrática y legitimidad, de manera que cuando se pone en tela de juicio el carácter representativo de la vicepresidencia, se está poniendo en cuestión la legitimidad de este cargo y, por extensión, del Ejecutivo. Para corregir esta tendencia de la vicepresidencia fija a amenazar la legitimidad del gobierno en sistemas presidencialistas es imprescindible una reforma institucional. Ésta puede tocar distintos niveles: desde la eliminación del cargo (que se ha planteado numerosas veces, tanto en Estados Unidos como en América Latina) hasta su transformación en una vicepresidencia elástica (es decir, que quien la ocupa pueda ser reemplazado por el presidente), la modificación de sus condiciones y mecanismos de elección, etcétera.

En Estados Unidos, a lo largo de los últimos dos siglos largos (desde la Constitución de 1787) se han incorporado numerosas enmiendas relativas a la vicepresidencia, de manera que no se trataría de un procedimiento novedoso o revolucionario. Se han ido abordando los conflictos conocidos a lo largo de 230 años y el cargo se ha ido modificando -incluso en algunos de sus rasgos esenciales- para servir mejor a los fines que el sistema político norteamericano requería en cada etapa. La xxv Enmienda (de 1967), por ejemplo, respondía al escenario de la Guerra Fría y la consiguiente necesidad de garantizar la continuidad del Ejecutivo ante todo. La prioridad era tal continuidad, y el carácter representativo del vicepresidente nominado a dedo devenía un rasgo secundario.

En América Latina, por el contrario, la combinación de marcos legales y cultura política generó una gran cantidad de conflictos vinculados a la vicepresidencia que, sin embargo, no dieron lugar a reformas institucionales que los amortiguaran en el futuro. Así, entre los numerosos obstáculos a la estabilidad democrática asociados a la vicepresidencia, está el déficit representativo.

Como se ha visto en el caso de Estados Unidos, ni siquiera una cultura política marcada por la lealtad institucional y 
una historia constitucional jalonada por reformas conducentes a una vicepresidencia más funcional han conseguido atenuar de forma suficiente cierta problemática vinculada a este puesto. Por otro lado, casos como los de México y Chile, donde no hay vicepresidente $y$, sin embargo, están preparados para sustituir al jefe del Ejecutivo en caso de muerte, renuncia o incapacidad, obligan a preguntarse si la mejor solución para el problema vicepresidencial podría ser su eliminación. A lo mismo conduce la observación de la vicepresidencia flexible presente, por ejemplo, en España -y en gran parte de los sistemas parlamentarios-: se garantiza allí la sucesión presidencial y se destierra todo peligro de acefalía, pero sin incorporar los peligros de un vicepresidente fijo, irremovible.

Frente a la histórica indiferencia por la vicepresidencia latinoamericana, el reciente aumento del interés académico por esta institución permite albergar optimismo: cabe esperarse que los tradicionales problemas de este cargo, combinados con los nuevos estudios que sacan tales problemas a la luz y proponen diversas soluciones, rompan el statu quo en que se encuentra la segunda magistratura en gran parte de las Américas.

\section{BibLIOGRAFÍA}

Andreoni, M., "Michel Temer, Brazil's Deeply Unpopular President, Signals Run for a New Term”, The New York Times, 24 de marzo de 2018, https://www.nytimes.com/2018/03/24/ world/americas/brazil-michel-temer.html

Aragón Reyes, M., Estudios sobre el Parlamento, Ciudad de México, unAM, Instituto de Investigaciones Jurídicas y Cámara de Diputados, 2017.

Armesto, D., "El vicepresidente de la nación. Su importancia institucional", El Derecho, 19 de septiembre de 2008, 12.094.

Badeni, G., "Las funciones del vicepresidente de la Nación", El Derecho, 11 de agosto de 2008. 
Baumgartner, J., The American Vice Presidency Reconsidered, Westport, Praeger Publishers, 2006.

BAYH, B., Presidential Disability and Succession, Indianápolis y Nueva York, The Bobbs-Merrill Company, 1968.

Berns, W., "The Insignificant Office. What the Framers Thought of the Vice Presidency", National Review Online, 9 de julio de 2004, http:/ / www.aei.org/include/pub_print.asp?pubID=20874

Bianchi, A., Historia de la formación constitucional argentina: 18101860, Buenos Aires, Lexis Nexis Argentina, 2007.

Bidart Campos, G., Manual de la Constitución reformada, Buenos Aires, Ediar, 1997.

Bidegain, G., "Vicepresidentes en América del Sur: una agenda de investigación", Colombia Internacional, 89, 9 de julio de 2004, pp. 159-188.

Castro, N., La sorprendente historia de los vicepresidentes argentinos, Buenos Aires, Javier Vergara Editor, 2009.

Cheibub, J. A. y F. Limongi, "Democratic Institutions and Regime Survival: Parliamentary and Presidential Democracies Reconsidered", Annual Review of Political Science, 5, 2002, pp. 151-79.

Ekmekdjí́n, M., Manual de la Constitución argentina, Buenos Aires, Depalma, 1999.

Feerick, J., "Presidential Succession and Inability: Before and After the Twenty-Fifth Amendment", Fordham Law Review, 79 (3) 2011, pp. 907-949.

Feliú. P., "Sobreviviendo a reformas, impopularidad y casos de corrupción: el presidencialismo de coalición del Brasil de Temer", Revista de Ciencia Política, 38 (2), 2018, pp. 181-206.

Goldstein, J., The Modern American Vice Presidency. The Transformation of a Political Institution, Princeton, University Press, 1982.

GonzÁlez, J., El Senado federal. Su constitución, facultades y privilegios. Dictámenes y discursos parlamentarios, Buenos Aires, La Facultad, 1919.

Hamilton, A., J. Madison y J. Jay, El Federalista, México, Fondo de Cultura Económica, 2001 (1780).

Jiménez BARCA, A., "El partido aliado de Rousseff deja el Gobierno y aísla a la presidenta todavía más”, El País, 30 de marzo de 
2016, https://elpais.com/internacional/2016/03/29/actualidad/1459264059_172547.html

JimÉnez BARCA, A., "Temer busca capear su profunda impopularidad", El País, 5 de agosto de 2016, https://elpais.com/internacional/2016/08/05/america/1470350121_159219.html

Jiménez BARcA, A., "El vicepresidente brasileño Michel Temer se ve ya como presidente", El País, 12 de abril de 2016, https:// elpais.com/internacional/2016/04/12/actualidad/1460484 960_263641.html

Kelsen, H., Esencia y valor de la democracia, Barcelona y Buenos Aires, Labor, 1934.

Levinson, S., "The Twelfth Ammendment, National Constitution Center", s/f, https://constitutioncenter.org/interactive-constitution/amendments/amendment-xii

Linz, J., Democracia Presidencialista o Parlamentaria, en Consejo para la Consolidación de la Democracia, Presidencialismo vs. Parlamentarismo, Buenos Aires, Eudeba, 1988.

Linz, J., "The Perils of Presidentialism", Journal of Democracy, 1 (1), 1990, pp. 51-69.

Linz, J. y A. Valenzuela (eds.), The Failure of Presidential Democracy, vol. 2. The case of Latin America, Baltimore, The Johns Hopkins University Press, 1994.

Maddalena, G., "Political Communication in the (Iconic) Trump Epoch", European View, 15 (2), 2016, pp. 245-252.

Mainwaring, S., "Presidentialism, Multipartism, and Democracy. The Difficult Combination”, Comparative Political Studies, 26 (2) 1993, pp. 198-228.

Mainwaring, S. y M. Shugart, "Juan Linz, Presidentialism and Democracy. A Critical Appraisal”, Comparative Politics, 29 (4) 1997, pp. 449-471.

Marsteintredet, L., "La vicepresidencia y los problemas de la sucesión presidencial en América Latina. Viejos y nuevos retos para el presidencialismo", Política y Gobierno, 26 (1) 2019, pp. 117-137.

Marsteintredet, L. y F. UgGla, "Allies and Traitors: Vice-Presidents in Latin America”, Journal of Latin American Studies, 2019, pp. 1-28, doi:10.1017/S0022216X18001098 
Mayka, L. R., "Bringing the Public into Policymaking: National Participatory Institutions in Latin America", tesis doctoral, Berkeley, University of California, 2013, https://digitalassets.lib.ber keley.edu/etd/ucb/text/Mayka_berkeley_0028E_13554.pdf

Mieres, P., "Las candidaturas vicepresidenciales en las campañas electorales. El caso de Uruguay 2009", ponencia presentada en el Cuarto Congreso de Ciencia Política de Uruguay, Montevideo, 14-16 de noviembre de 2012.

Mieres, P. y E. Pampín, "La trayectoria de los vicepresidentes en los regímenes presidencialistas de América”, Revista de Estudios Políticos, 167, 2015, pp. 99-132.

Neale, T., The Electoral College: How It Works in Contemporary Presidential Elections, CRS Report RL32611, Congressional Research Service, 2017, https://fas.org/sgp/crs/misc/RL32611.pdf

Pignataro, A. y M. Taylor-Robinson, "Party competition, gender quotas, and enhanced inclusiveness in the selection of vice-presidential candidates", Politics, Groups, and Identities, 9:4, 2021, pp. 721-738, doi: 10.1080/21565503.2019.1637354

Plowden, E., Commentaries, or Reports, Londres, S. Brooke, 1816 (1571).

Purcell, L. E. (ed.), The Vice Presidency: A Biographical Dictionary, Nueva York, Facts on File, 1998.

Redondo, J., "Orígenes y justificación del presidencialismo americano”, Cuadernos de pensamiento político, 47, 2015, pp. 53-68.

Ross-Ackerman, S., "Hyper-presidentialism: Separation of Powers without Check and Balances in Argentina and Philippines", Berkeley Journal of International Law, 29 (1) 2011, pp. 246-333.

Schlesinger, A., Jr., "On the Presidential Succession", Political Science Quarterly, 89 (3) 1974, pp. 475-505.

Serrafero, M., El poder y su sombra. Los vicepresidentes, Buenos Aires, Editorial de Belgrano, 1999.

Serrafero, M., "La vicepresidencia y las coaliciones políticas: el caso de Argentina”, Revista de Sociologia e Política, 26 (65) 2018, pp. 15-38.

Silberdick Feinberg, B., Next in Line: The American Vice Presidency, Danbury, Franklin Watts, 1996. 
Sribman Mittelman, Ariel, "La vicepresidencia argentina (19832009)", Cadernos de Estudos Latino-Americanos, 10, 2011.

Sribman Mittelman, Ariel, La sucesión del poder. Una aproximación general desde experiencias de los siglos XX y XXI, Salamanca, Ediciones Universidad, 2015.

Sribman Mittelman, Ariel, "La vicepresidencia en América Latina: un mal innecesario", América Latina Hoy, núm. 81, 2019, pp. $51-75$.

Sribman Mittelman, Ariel, "La vicepresidencia en México: un debate pendiente”, Revista Estudios Políticos, núm. 48, 2019, pp. 73-94.

Sribman Mittelman, Ariel, "Los principios de disponibilidad e inmediatez en la vicepresidencia latinoamericana", Res Publica. Revista de Historia de las Ideas Políticas, vol. 24, núm. 2, 2021, pp.161-172, https://doi.org/10.5209/rpub.70008

TocQueville, A. de, La democracia en América 1, Madrid, Alianza, 1980 (1835).

UGGLA, F. (2020). The politics of vice-presidential selection in Latin America. Electoral Studies, 2020, https://doi.org/10.1016/j. electstud.2020.102154

Vintró, J., "El Rey y la investidura del Presidente del Gobierno", Agenda Pública / El País, 21 de enero de 2016, agendapublica. elpais.com/el-rey-y-la-investidura-del-presidente-del-gobierno

Walch, T. (ed.), At the President's Side. The Vice Presidency in the Twentieth Century, Columbia, University of Missouri Press, 1977.

Weyland, K., The Politics of Market Reform in Fragile Democracies: Argentina, Brazil, Peru, and Venezuela, Princeton, University Press, 2002.

Young, D., American Roulette. The History and Dilemma of the Vice Presidency, Nueva York, Holt, Rinehart and Winston, 1972. 
